\title{
Fatores críticos para implementação de gerenciamento por projetos: o caso de uma organização de pesquisa
}

\author{
Roque RABechinI JR. \\ Doutorando do Depto. de Eng. Produção - Escola Politécnica da USP \\ E-mail: roquejr@usp.br \\ Marly Monteiro de Carvalho \\ Profa. Dra. do Depto. de Eng. Produção - Escola Politécnica da USP \\ E-mail: marlymc@usp.br \\ Fernando José Barbin LaUrindo \\ Prof. Dr do Depto. de Eng. de Produção da Escola Politécnica da USP \\ E-mail: fjblau@usp.br
}

\begin{abstract}
Resumo
O número de empresas que estão adotando a metodologia de gerenciamento de projetos tem crescido significativamente nos últimos anos. Contudo, poucas empresas brasileiras têm desenvolvido um modelo de gerenciamento de projetos. Para as empresas que buscam uma vantagem competitiva pela inovação, gerar competências em projeto passa a ser fundamental. E para atingir o sucesso em projetos é preciso balancear as expectativas dos interessados aos recursos disponíveis, utilizando conceitos, ferramentas e técnicas para obter a excelência no gerenciamento de projetos. Com o intuito de identificar os fatores críticos de sucesso para a implementação do gerenciamento de projetos numa organização, este artigo mostra o resultado de um estudo de caso realizado em uma instituição de pesquisa. A análise pautou-se em aspectos relacionados às competências em projetos, tanto na busca de eficiência e de eficácia, como nos aspectos de maturidade organizacional.
\end{abstract}

\section{Palavras-chave}

Gerenciamento de projetos; Gestão da inovação; Instituição de pesquisa tecnológica.

\section{Critical Factors for implementation of Project Management: a Research Organization case}

\begin{abstract}
The project management methodology has been increasingly applied in companies nowadays. Nevertheless, in Brazilian panorama it is also difficult to verify the adoption of formal project management program.

Companies searching for competitive advantages through innovation must have competencies in project management. Meeting project efficiency involves balancing scope expectations and the available resources. Thus, project management addresses the full range of concepts, tools and techniques to improve project performance and organizational effectiveness and efficiency.

The main purpose of this paper is to investigate projects competencies management practices. The adopted methodological approach was a case study in a Research Organization. The analysis was performed based on two major approaches: the first one is the project effectiveness and efficiency evaluation (tasks and results], and the second one is the organizational maturity.
\end{abstract}

Key words

Project management; Managing innovation, Technological research organization. 


\section{NECESSIDADES DE} MUDANC̣AS - INTRODUC̣ÃO

Identificar quais competências uma empresa precisa construir para ganhar e manter uma vantagem competitiva num mercado em constante mutação é uma tarefa árdua. Contudo, a capacidade de inovação e a de gestão do conhecimento parecem ser habilidades relevantes no cenário competitivo que se avizinha.

Porter (1998) já destacava as empresas inovadoras como fundamentais no desenvolvimento econômico das nações mais competitivas, tanto em função de sua maior rentabilidade, quanto devido à natureza dos empregos que geram, que demandam maior qualificação, obtendo em contrapartida melhor remuneração. Destaca-se, neste contexto, o caso das pequenas empresas de tecnologia do Vale do Silício, que mantêm altas taxas de crescimento e rentabilidade, mantendo-se em patamares de crescimento superiores ao restante da economia norte-americana.

Autores como De Masi (2000) e Handy (1995) enfatizam a inteligência como o principal ativo das empresas no cenário competitivo pós-industrial. Handy (1995) destaca ainda que este tipo de empresa será parecido com um "condomínio", onde grupos de projetos coabitam.

Kanter (1998) argumenta que a motivação das pessoas neste novo ambiente de trabalho está intrinsecamente atrelada ao engajamento em projetos criativos, que geram desafios levando as pessoas a investir energia física e mental para solucioná-los.

Contudo, um estudo baseado em empresas brasileiras mostrou que poucas têm formalizado e desenvolvido um modelo de gerenciamento do processo de inovação e de projetos (RABECHINI Jr. et al., 1996).

Com o intuito de apresentar os fatores críticos de sucesso para a implementação do gerenciamento de projetos, este artigo mostra o resultado de um estudo de caso realizado em uma organização voltada à pesquisa tecnológica, em que a atividade de projetos é fundamental. A análise pautou-se em aspectos relacionados às competências em projetos, tanto na busca de eficiência como de eficácia, como nos aspectos de maturidade organizacional.

\section{REVISÃO DA LITERATURA - IMPORTÂNCIA DOS PROJETOS NA ESTRATÉGIA DA EMPRESA}

No cenário competitivo atual, a sobrevivência depende da interação com seu meio através do atendimento ideal ao seu cliente e posicionamento adequado em seu mercado, frente a seus concorrentes. Para isto, é necessário que as organizações estejam sempre buscando a inovação, seja em seus produtos, em seus processos ou em seus serviços. A inovação como elemento crucial de vantagem competitiva ocorre, por exemplo, através de lançamentos de novos produtos que, por sua vez, garantem a captura de parcelas de mercado, bem como da manutenção de clientes ávidos por novidades, gerando, portanto, retornos de investimento às empresas. Alguns exemplos, que já são clássicos, mostram que empresas conseguem vantagens significativas ao se dedicarem à inovação - Citibank, o pioneiro dos serviços por caixas eletrônicos; Benetton, pelo uso de sofisticados sistemas de tecnologia de informação; entre outros (AVISON et al., 1996), (DUHAN et al., 2001).

Tidd et al. (1997) construíram uma tipologia de inovação e avaliaram seus possíveis impactos na estratégia competitiva, conforme mostra a Tabela 1.

No entanto, para que a inovação possa ser incorporada à cultura de uma organização, deve-se encará-la como um processo que pode ser gerido, visando desenvolver e explorar o novo conhecimento, em seus aspectos técnicos e comerciais. Segundo Tidd et al. (1997), o processo de inovação requer abstração, que pode ser comum a todas as organizações e compõe-se dos seguintes elementos:

- Varredura ambiental - esta fase visa identificar e processar os sinais do ambiente interno e externo à organização sobre as ameaças e oportunidades;

- Decisão - esta fase, baseada na visão estratégica da

Tabela 1: Vantagens estratégicas pela inovação.

\begin{tabular}{|l|l|}
\hline \multicolumn{1}{|c|}{ Tipo de Inovação } & \multicolumn{1}{c|}{ Vantagem Estratégica } \\
\hline Novidade & Oferecer alguma coisa que outras empresas ainda não ofereceram. \\
\hline Mudança & Reescrever as regras do jogo da competição. \\
\hline Complexidade & Dificultar que concorrentes aprendam sua tecnologia - criação de barreiras. \\
\hline Projeto robusto & Modelo de produto ou processo visando esticar o ciclo de vida do produto. \\
\hline Inovações incrementais contínuas & Movimento contínuo de melhoramento do custo/performance \\
\hline
\end{tabular}

Fonte: (TIDD et al., 1997) 
organização, visa interpretar os sinais e optar pela melhor alternativa de ação;

- Recursos - uma vez escolhida a alternativa, a organização deverá encontrar recursos para viabilizá-la; e

- Implementação - desenvolver a tecnologia (inovação) e disponibilizá-la interna ou externamente.

Um estudo baseado em empresas brasileiras mostrou que poucas têm formalizado e desenvolvido um modelo de gerenciamento do processo de inovação (RABECHINI Jr. et al., 1996). O estudo mostrou que as práticas de monitoramento da inovação tecnológica podem ser classificadas em quatro categorias, segundo o tipo da empresa. A primeira categoria é caracterizada pelas empresas que já possuem um sistema de monitoramento tecnológico estabelecido (procedimentos de pesquisa, triagem, avaliação e apresentação) e bastante informatizado (uso intensivo de WAN - Wide Area Network, LAN - Local Area Network e programas de gerenciamento de banco de dados, por exemplo). Nesta categoria estão incluídas as grandes empresas multinacionais.

A segunda categoria refere-se às empresas cuja prática do monitoramento da inovação tecnológica é ainda incipiente (procedimentos de sistematização em estágios iniciais e em evolução) e cujo sistema começa a ser informatizado. Nesta categoria estão inseridas algumas empresas nacionais do setor eletroeletrônico e de informática.

\section{- Apropriada Estrutura Organizacional}

Um reflexo de uma estrutura organizacional aderente às estratégias da empresa é sua comunicação. Nas empresas inovadoras a comunicação não é transmitida de cima para baixo seguindo um só caminho e, normalmente, é compartilhada por um número significativo de interessados de forma a atenderem seus requisitos. Há pelo menos três variáveis a serem consideradas na gerência da inovação: informação, tempo e pessoas. As empresas que melhor gerenciam a inovação são aquelas que disponibilizam $a$ informação certa para a pessoa certa na hora certa. Esta capacidade só é conseguida através de um processo de gerência do sistema de comunicação que no seu estágio de maior abrangência constitui-se no que é hoje chamado de gestão do conhecimento. Segundo Terra (1998), "a teoria organizacional e as necessidades impostas pelo ambiente têm evoluído no sentido de promover uma crescente participação da contribuição intelectual dos trabalhadores e uma gestão pró-ativa da criatividade, da aprendizagem e do conhecimento".

\section{- Papéis-Chave na Organização}

Estes elementos têm um caráter implícito, mas fundamental para a caracterização e o sucesso de empresas inovadoras. São funcionários que estimulam a inovação, os gatekeepers, entre outros, que desempenham papéis que podem direta ou indiretamente promover a inovação na empresa.

\section{0 ara as empresas que buscam uma vantagem competitiva pela inovação, gerar competências em projeto passa a ser fundamental.}

\section{- Treinamento}

Uma característica básica associada ao alto desempenho das organizações é sua capacidade de acompanhar a evolu-
A terceira categoria compreende as empresas que praticam o monitoramento tecnológico de forma ainda incipiente, com as informações ainda não informatizadas. Esta categoria inclui uma empresa nacional que considera importante a tecnologia para atingir maior competitividade. E a quarta categoria refere-se àquelas empresas que não realizam o monitoramento tecnológico. Nesta categoria estão incluídas pequenas empresas nacionais.

Uma empresa inovadora pode ser entendida como aquela que apresenta uma preocupação estratégica eminente com a inovação e, como consequiência, tem construído um processo formalizado de gerenciamento da inovação. Tidd et al. (1997) levantaram os principais componentes desta empresa:

\section{- Visão e Liderança para Inovação}

Este componente refere-se à postura em relação aos riscos intrínsecos da inovação, essencial para a formação de uma empresa inovadora. ção do mercado em que estão inseridas. Isto somente pode ser feito através de investimentos constantes em treinamento e desenvolvimento dos funcionários, para que possam compreender um novo sistema, operar uma nova máquina, entender o comportamento de um concorrente, etc.

\section{- Envolvimento com Inovação}

Talvez o exemplo mais notório de empresa envolvida com inovação seja a $3 \mathrm{M}$, que contabiliza $15 \%$ do tempo de um grupo de funcionários para que eles possam pensar em "coisas novas". Mais uma vez a inovação sai do ambiente laboratorial característico da P\&D para tornar-se algo mais comunitário em termos da empresa.

\section{- Equipe}

A capacidade de balancear os recursos disponíveis através da formação de equipes eficientes é mais um elemento de empresas inovadoras. Já que a inovação pode ser carac- 
terizada pela combinação de diferentes perspectivas em resolução de problemas, a formação de equipes com capacidade em fluência de idéias e em flexibilidade de soluções torna-se fundamental para uma empresa inovadora. sões, objetivos, metas e estratégias dessas organizações. Para King (1983), quando as relações entre estes elementos forem "bem definidas, cuidadosamente concebidas e analisadas" um plano de projetos tem chances de ser implementado. Caso contrário, os planos irão representar apenas um

\section{- Clima Criativo}

O ambiente criativo numa organização requer justamente essa capacidade em promover a fluência e flexibilidade. Assim, para construir um clima criativo recomenda-se que haja desenvolvimento de política e procedimentos de comunicação, sistemas de recompensas, treinamento, apropriada estrutura organizacional, etc.

\section{- studo baseado em empresas - brasileiras mostrou que poucas têm formalizado e desenvolvido um modelo de gerenciamento do processo de inovação.}

\section{- Foco Externo}

Este elemento refere-se aos estímulos que vêm de fora da organização. Na verdade, quando a empresa tem um foco externo, ela tem a capacidade de interpretar os sinais que possam ameaçar ou gerar oportunidades, sendo inovadoras, terá um processo para gerenciar estes sinais e responder o mais rapidamente possível ao mercado.

\section{- Comunicação}

Dada uma apropriada estrutura organizacional, este elemento refere-se ao uso de múltiplos canais. A comunicação não deve ser considerada de forma restrita, seu sentido deve ser amplo. Mecanismos que garantem essa amplitude incluem: trabalho rotativo; equipes e projetos; desenvolvimento de políticas e sessões de revisão; notas de equipe; e multimídia - vídeo, notícias eletrônicas, etc.

- Organização que aprende ("learning organization")

Como visto no tópico referente à estrutura organizacional apropriada, a gestão do conhecimento tem sido hoje foco de estudos no âmbito das empresas. Neste sentido, inovação pode representar um ciclo de aprendizado envolvendo um processo de experimentação, experiência, reflexão e consolidação.

Os elementos mencionados acima são cruciais para caracterizar uma organização inovadora. O gerenciamento por projetos é aderente a vários desses elementos, quer na incorporação de seus conceitos vis-à-vis aos da referida disciplina, quer na prática de cada um. Assim, a concepção das estruturas organizacionais aqui mencionadas é fonte de estudo da disciplina gerência de projetos, bem como das preocupações com comunicação, equipes, etc. Certamente, o gerenciamento por projetos, quando desenvolvido nas organizações inovadoras, pode contribuir para a eficiência de suas operações. Em um estudo sobre organizações que trabalham com projetos, King (1983) ressalta a relação da abordagem por gerenciamento de projetos alinhada às mis- volume de documentos que requer tempo substancial de desenvolvimento e energia para preparação mas que, no entanto, dificilmente serão implementados.

Desta forma, entender o processo em que uma organização se encontra será fundamental para traçar ações referentes à implementação de um programa de gerenciamento de projetos.

\section{Gerenciamento de Projetos}

O conceito de projetos tem sido discutido e tem evoluído ao longo dos últimos anos. A norma ISO 10006 (1997), por exemplo, define projeto como sendo "um processo único, consistindo de um grupo de atividades coordenadas e controladas com datas para início e término, empreendido para o alcance de um objetivo conforme requisitos específicos, incluindo limitações de tempo, custo e recursos".

Já para o PMI - Project Management Institute, um projeto pode ser definido, em termos de suas características distintivas, como sendo "um empreendimento temporário feito para criar um produto ou serviço único" (PMBoK, 2000).

Uma das mais completas e convincentes definições de projeto proposta por Tuman (1983) diz que "um projeto é uma organização de pessoas dedicadas visando atingir um propósito e objetivo específico. Projetos geralmente envolvem gastos, ações únicas ou empreendimentos de altos riscos no qual tem que ser completado numa certa data por um montante de dinheiro, dentro de alguma expectativa de desempenho. No mínimo todos projetos necessitam de terem seus objetivos bem definidos e recursos suficientes para poderem desenvolver as tarefas requeridas".

Este conceito pode ser expandido e levar ao entendimento sobre gerenciamento de projetos. Segundo o PMI Project Management Institute (PMBoK, 2000), gerenciamento de projetos requer aprimoramento da administração de nove áreas de conhecimento vinculadas a processos gerenciais. Estas áreas se referem à integração dos diversos 
elementos-chave de um projeto, alguns essenciais, outros facilitadores, quais sejam: integração, escopo, prazos, custos, recursos humanos, aquisições, qualidade, riscos, comunicação do empreendimento.

A excelência nestas áreas permite atingir o sucesso no gerenciamento de projetos, conforme definido pelo (PMBoK; 2000): "aplicação do conhecimento, habilidades, ferramentas e técnicas às atividades do projeto a fim de atender ou superar as necessidades e expectativas que os interessados (stakeholders) possuem no projeto".

Pinto \& Sleven (1983) partem do pressuposto que um projeto é considerado um sucesso em sua implementação, caso atenda a quatro critérios - tempo, custo, eficácia e satisfação do cliente. Com base nestes critérios, esses autores constituíram um grupo de 50 gerentes de projetos que trabalharam com os aspectos sucesso na implementação de gestão de projetos e estabeleceram o modelo dos dez fatores críticos de sucesso.

No campo de estudo de projetos, a proposição de Pinto \& Sleven (1983), sobre fatores críticos de sucesso, apresenta algumas evidências de que há aderência com os elementos identificados por Tidd et al. (1997) sobre o gerenciamento da inovação. Olhando os fatores críticos de sucesso percebem-se melhor tais evidências.

\section{- missão do projeto;}

Refere-se à definição clara dos objetivos no início do projeto. Enfatiza a visão que os interessados possam ter dos compromissos do projeto.

\section{- suporte gerencial;}

Refere-se a autoridade e poder existentes na organização para gerenciar os recursos do projeto. Os interessados, considerando-se este fator, em geral, estimulam o desenvolvimento de projetos e uso da abordagem de gerenciamento de projetos.

\section{- planejamento;}

Este fator refere-se ao estabelecimento das atividades individuais do projeto. Como conseqüência destaca-se a preparação para o gerenciamento de recursos coletivos (equipes) e materiais.

\section{- cliente consultor;}

Este trata da comunicação com os clientes do projeto.

- questões de administração de pessoal;

Refere-se a alocação (recrutamento, seleção e treinamento) das necessidades em pessoal para o projeto.

- tarefas técnicas;

Disponibilidade e competência para acompanhar as tare- fas técnicas. Envolvimento com atividades inovativas é essencial para a configuração deste fator.

- aceite do cliente;

Refere-se ao estágio final do projeto e à "venda" dos resultados. É imprescindível, portanto, um foco externo ao ambiente de projetos.

\section{- monitoramento;}

Capacidade de dar feedback em todos os estágios do projeto.

\section{- comunicações;}

Formar uma rede de transmissão da informação no âmbito do projeto.

\section{- gerência conciliadora.}

Capacidade de superar as inesperadas crises decorrentes do plano do projeto, conciliando as expectativas dos vários interessados.

A contribuição do estudo proposto por Pinto \& Sleven, (1983) como vista, é relevante e específica ao ambiente que contorna o gerenciamento de projetos. No âmbito da organização, no entanto, o estudo de Kerzner (2000) proporciona uma investigação sobre a maturidade em gerenciamento de projetos considerando-se cinco fases de um ciclo de vida genérico, quais sejam: embrionária; reconhecimento da alta administração; reconhecimento da média gerência; crescimento; e maturidade (CARVALHO et al., 2002). A Figura 1 ilustra o modelo.

As principais características da fase embrionária referem-se ao reconhecimento da importância do gerenciamento de projetos para a empresa. O reconhecimento da importância do gerenciamento de projetos pela alta administração pode ser percebido pelos seguintes pontos: visibilidade em termos de suporte; entendimento da disciplina de gerenciamento de projetos; estabelecimento de patrocinador no nível executivo; postura favorável na mudança da forma de fazer negócios. As principais características da terceira fase referem-se à gerência de linha. A fase de crescimento é caracterizada pelo desenvolvimento de uma metodologia de gerenciamento de projetos pela empresa e comprometimento com as atividades de planejamento. A última fase, a de maturidade, refere-se ao desenvolvimento de um sistema formal de controle gerencial que integre custos e prazos, além do desenvolvimento de um programa educacional com o intuito de aumentar as competências em gerenciamento de projetos na empresa.

As competências em gerenciamento de projetos no âmbito da empresa também foram estudadas por Frame (1999), cujo modelo evidencia sete elementos: procedimentos claros e bem formulados; acesso à informação; recursos huma- 
nos e materiais com quantidade e qualidade suficiente; oportunidades para treinamento; visão clara dos objetivos da empresa; cultura para melhoria contínua; e institucionalização do gerenciamento de projetos.

Os elementos teóricos abordados enfatizam o ambiente de atividades inovativas, não rotineiras e mais especificamente o gerenciamento de projetos. Com base neste quadro conceitual teórico foram traçados os objetivos deste trabalho e tratados segundo os fundamentos metodológicos a seguir considerados.

\section{ASPECTOS METODOLÓGICOS}

Com o objetivo de melhor identificar os fatores críticos no gerenciamento de projetos, tanto no que concerne às competências no âmbito da organização, como nos aspectos estratégicos e táticos, optou-se pela abordagem de estudo de caso, que permitiria analisar estes fatores (YIN, 1991)

Os critérios para a escolha do caso a ser analisado foram: a existência de atividades de inovação; a existência de estrutura organizacional matricial; a existência de atividades de projeto.

Com base nestes critérios, foi selecionado o caso de uma empresa nacional que desenvolve pesquisa tecnológica e serviços técnicos especializados, em diferentes áreas de atuação. Uma vez selecionado o caso, foram levantados dados de projetos e feitas entrevistas com diversos atores de diferentes níveis hierárquicos da corporação.

Para um estudo mais detalhado das atividades de gerenciamento de projeto foi selecionada uma amostra de 14 projetos com impacto estratégico na organização, com base no faturamento. Os gerentes e equipe dos projetos da amostra participaram de entrevistas, cujo roteiro foi dividido, basicamente, em três seções: informações gerais, porte dos projetos (nos últimos dois anos) e dados sobre possíveis problemas (fatores críticos de sucesso) em projetos.

A primeira seção do roteiro, informações gerais, contém questões que visam caracterizar a função do entrevistado, sua experiência, capacitação e a área de atuação.

$\mathrm{Na}$ seção seguinte são apresentadas as questões sobre o porte dos projetos nos quais os entrevistados trabalharam, com base nos últimos dois anos. O porte do projeto é avaliado de acordo com o número de pessoas que participaram da equipe, o valor do projeto em reais e com a sua duração.

Na última seção estão as questões referentes ao projeto em si e seus possíveis fatores de sucesso/fracasso, visando focalizar a demanda por informação de planejamento e controle. Os dados que compõem esta seção contêm informações sobre: a) definição dos objetivos; b) envolvimento do cliente; c) habilidades do gerente de projetos; d) planejamento; e) custo (esta é uma das variáveis mais sensíveis ao sucesso do projeto); f) comunicação; g) técnica.

Figura 1: Ciclo de vida em gerenciamento de projetos.

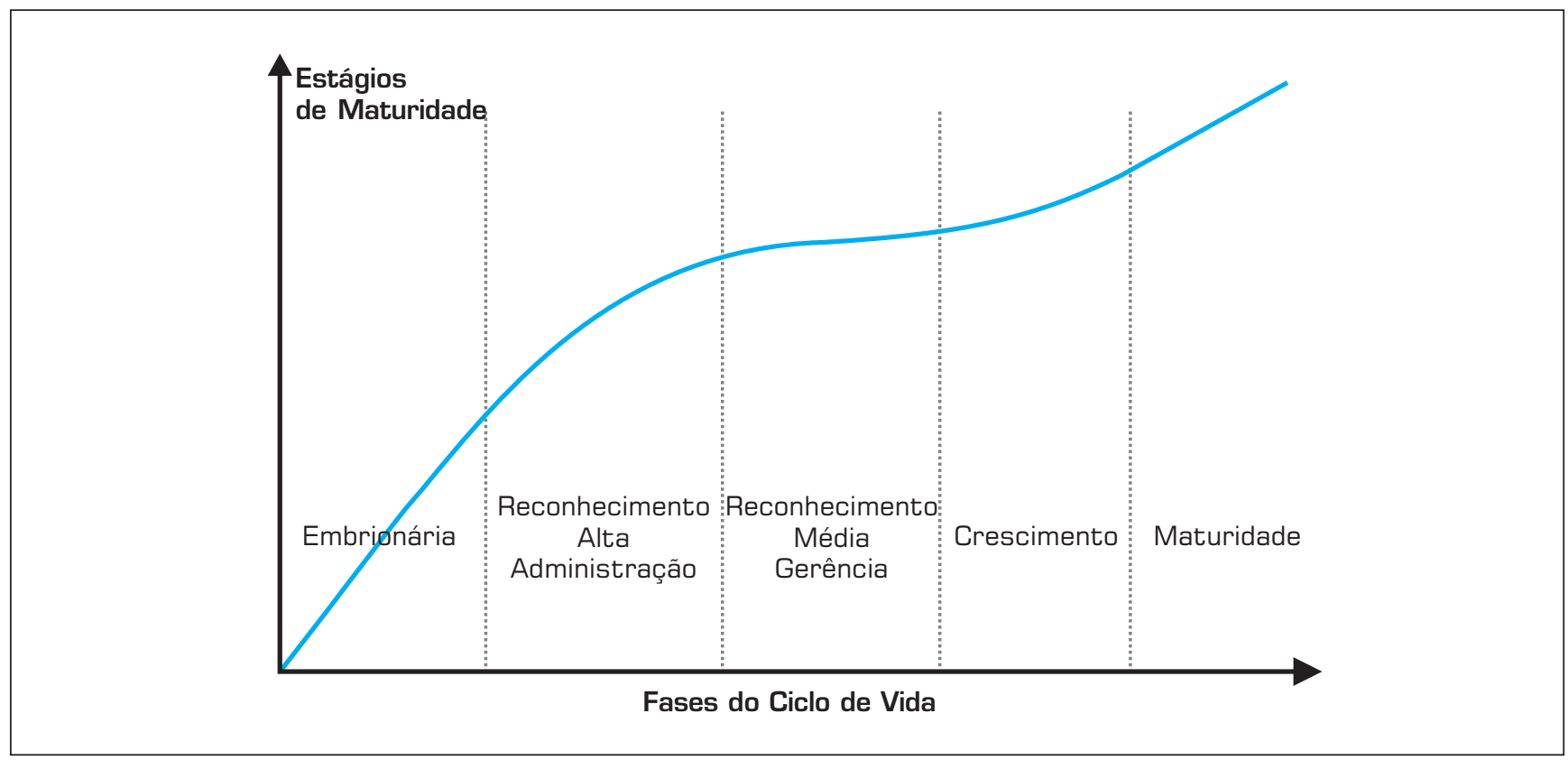

Fonte: (KERZNER; 2000). 


\section{O ESTUDO DE CASO}

A Organização de Pesquisas estudada é uma das maiores da América Latina, constituída na forma de empresa de capital aberto, com a maior parcela da ações pertencentes à esfera pública estadual, contando com cerca de 1.500 funcionários, atuando em diversas áreas, das mais tradicionais da engenharia até tecnologia da informação e telecomunicações. za e a complexidade inerentes aos projetos de pesquisa tecnológica constituem uma barreira a este tipo de controle e avaliação, bem como julgam que estes controles tomam tempo precioso da atividade de pesquisa. Já a avaliação nos serviços técnicos especializados é encarada com maior naturalidade, tanto no que concerne a custo e a prazo, como a satisfação do cliente.

Ressalte-se ainda que, numa pesquisa realizada em 1994 com 11 gerentes de projeto de P\&D da Organização, foi constatado que existe resistência dos pesquisadores quanto à necessidade de quantificação das metas, bem como dificuldade em discernir entre objetivos, metas e marcos temporais, com uso freqüente de objetivos e/ou marcos temporais no lugar das metas (LANDGRAF et al., 1994).

No intuito de criar instrumentos que aprimorassem seu processo de tomada de

Atualmente, a autonomia financeira impõe-se como estratégia de viabilização da Organização, dado o quadro de alocação de verbas públicas traçado desde 1999. Isto ocorreu devido ao ajuste feito no orçamento da União, que repercutiu nos Estados, através de uma redução de 20\% na transferência dos recursos. No caso do Estado de São Paulo, onde se localiza a Organização, o governo anunciou que priorizaria a área social. Portanto, faz-se necessário um plano consistente com o cenário que se apresenta, ou seja, a redução da dotação orçamentária.

Este cenário não é propriamente uma novidade para a Organização, que, ao longo da década de 90 , viu seu corpo de funcionários ser reduzido à metade do que fora na década de 80. Além do enxugamento, a Organização vem tentando mudar sua relação com o governo do Estado de São Paulo, diminuindo sua dependência orçamentária, sendo mais agressiva na captação de recursos, públicos e privados.

Esta nova estratégia trouxe alguns reflexos no modelo de gestão adotado na Organização. Além da profunda redução dos quadros, verifica-se uma maior focalização nas áreas de maior excelência, bem como maior preocupação com a satisfação do cliente e implementação de programas de Qualidade \& Produtividade, tendo conseguido o certificado ISO9002 recentemente. Não obstante, estes esforços ainda são incipientes e ainda enfrentam resistência interna na adoção das novas técnicas de gestão.

Estudos realizados no âmbito do programa de Qualidade da Organização (CARVALHO, 1997) apontam os pesquisadores como elementos de resistência à adoção de sistemas de controle de projetos mais detalhados, principalmente do pessoal envolvido em atividades de Pesquisa \& Desenvolvimento $(\mathrm{P} \& \mathrm{D})$. Estes costumam argumentar que a incerte- decisão e controle, a Organização sentiu a necessidade de implementar um programa de Gerenciamento por Projetos, objeto de análise do presente estudo.

\section{RESULTADOS DAS ENTREVISTAS - TRADIC̣ÃO VERSUS INOVAC̣̃̃O}

Os resultados conseguidos da pesquisa chamam a atenção para o excelente nível de desenvolvimento técnico e inovativo da organização, de um lado. Mas, com um olhar um pouco mais cauteloso, por outro lado, descobre-se que há uma carência grande em gerenciamento de projetos.

Além de caracterizar a amostra, a análise dos dados levantados pautou-se na identificação do perfil dos projetos da organização, na demanda por treinamento e na caracterização dos projetos e os aspectos referentes ao seu gerenciamento.

\section{Caracterização da amostra}

Os funcionários que fizeram parte da amostra foram selecionados a partir de um conjunto de projetos de impacto estratégico, desenvolvidos na Organização nos últimos quatro anos. A esta relação foi acrescida outra, composta de projetos menores, visando ampliar a representação das áreas técnicas da Organização.

Em termos da função que os entrevistados desempenharam nos projetos selecionados, notou-se uma participação equilibrada na pesquisa, ou seja, o número de técnicos (44\%) foi próximo ao número de gerentes (56\%). Já os dados referentes à experiência destes funcionários revelaram uma maturidade considerável dos gerentes - a maioria $(85,71 \%)$ tem mais de 10 anos de experiência. 


\section{Perfil dos projetos}

Dos projetos selecionados, nota-se que a maioria $(60 \%)$ é caracterizada por equipes formadas entre 5 e 10 pessoas. Os projetos com mais que 10 pessoas representam $24 \%$ da amostra, restando, portanto, $16 \%$ de projetos com menos pessoas (ver Figura 2).

\section{Figura 2: Caracterização de equipes de projetos}

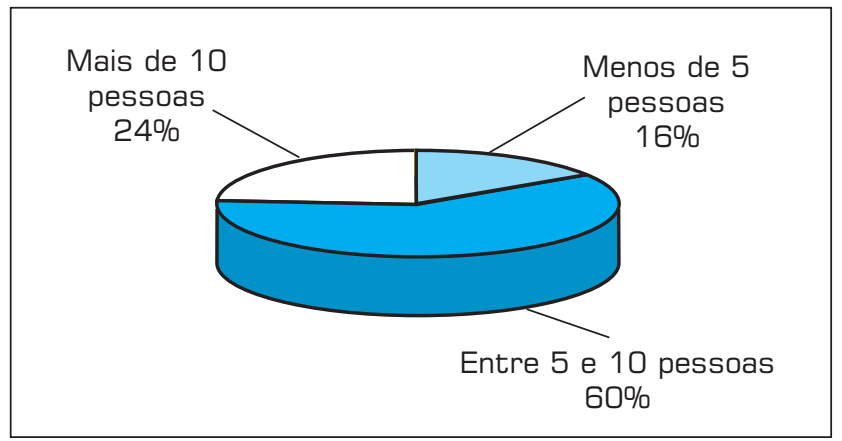

Em termos de valor, os grandes projetos, aqueles cujas receitas estimadas são maiores do que $\mathrm{R} \$ 100$ mil, representam $72 \%$ da amostra. Dos projetos restantes, $16 \%$ estão compreendidos na faixa que vai de $\mathrm{R} \$ 50$ mil a $\mathrm{R} \$ 100 \mathrm{mil}$, $8 \%$ entre $\mathrm{R} \$ 30$ mil a $\mathrm{R} \$ 50$ mil e apenas $4 \%$ de projetos têm receitas estimadas menores que $\mathrm{R} \$ 30$ mil (ver Figura 3).

Figura 3: Valor dos projetos da amostra [em $\mathrm{R} \$$ ]

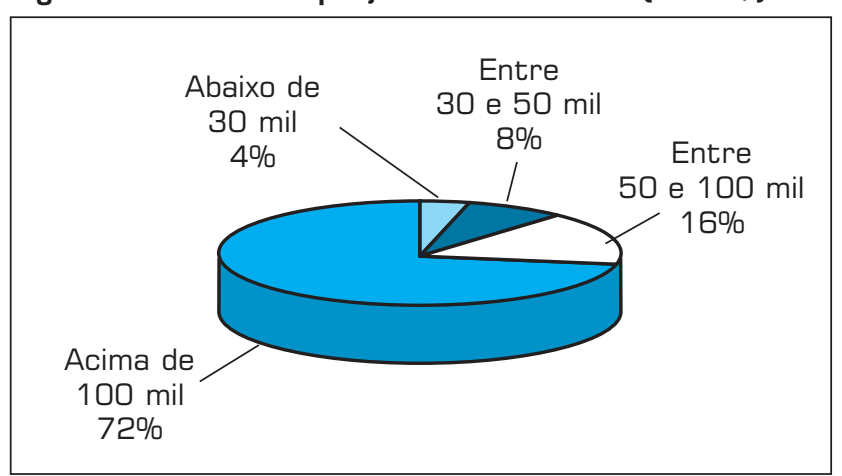

Os projetos selecionados não são classificados como de longa duração (maior do que um ano). Em geral, 44\% deles têm prazo estimado de duração maior do que um ano. A maioria está entre 6 e 12 meses (40\%) e entre 3 e 6 meses $(16 \%)$ (ver Figura 4).

Observando o perfil dos projetos da amostra, pode-se dizer que o tipo mais incidente foi aquele composto por uma equipe entre 5 e 10 pessoas, cujo valor está acima dos $\mathrm{R} \$ 100$ mil. Quanto à duração, pode-se constatar que 56\% dos projetos duram menos do que um ano, embora a categoria de maior incidência seja a de grandes projetos (acima de 12 meses).
Figura 4: Prazos dos projetos selecionados (em meses).

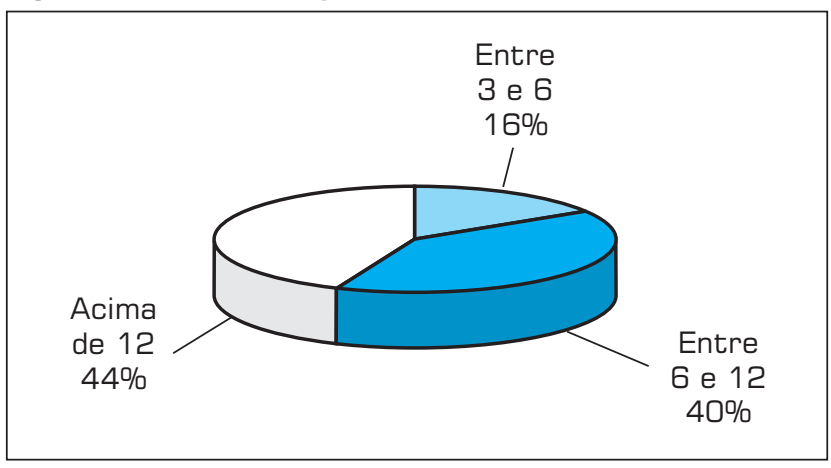

\section{Demanda por treinamento}

Foi perguntado aos gerentes sobre o treinamento recebido para desempenhar função adequada nos projetos em que trabalharam. A maioria (63\%) revelou que não recebeu nenhum treinamento. Uma parte (25\%) preparou-se através de convênio firmado entre a Universidade de São Paulo, representada pela FEA (Faculdade de Economia e Administração) e a Organização. Os $12 \%$ restantes, distribuídos eqüitativamente, tiveram alguma formação, ou através de cursos pontuais previstos pelo projeto ou através de projeto específico (programas de fomento governamentais). Havia, portanto, uma necessidade latente de treinamento em Gerência de Projetos entre os gerentes da amostra que hoje está explicitada (ver Figura 5).

\section{Figura 5: Realização de treinamentos recentes}

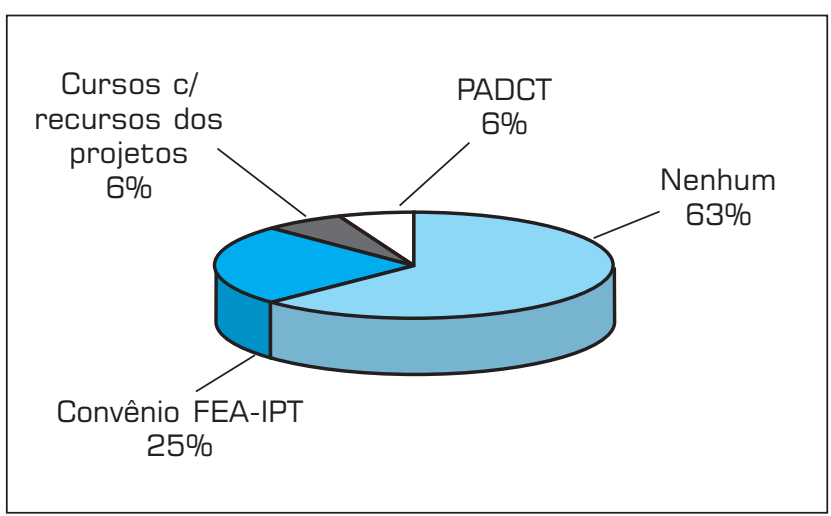

Quanto às necessidades percebidas em treinamento, constatou-se que, embora com um índice significativo de entrevistados que não responderam (21\%), a disciplina Gerência de Projetos foi apontada como tema de cursos com ênfase gerencial/administrativa por $48 \%$ dos entrevistados e com ênfase em recursos humanos por $14 \%$. Nota-se que há necessidades também de cursos sobre uso de ferramentas (10\%) e sobre marketing e negócios (7\%), conforme Figura 6. 
Figura 6: Demanda por treinamento.

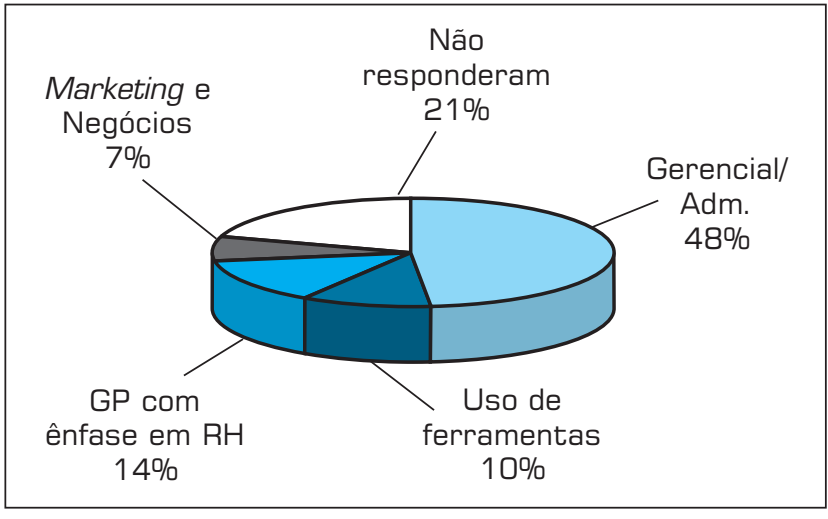

\section{Caracterização dos projetos}

De forma geral, percebe-se que na Organização os funcionários registram as informações sobre os projetos através de planilha padrão do sistema de acompanhamento de horas trabalhadas $(63,64 \%)$. Outras modalidades de acompanhamento foram citadas, o que reflete a tentativa de melhorar o controle em relação aos projetos; as mais significativas foram: planilhas de custo $(15,15 \%)$ e através de sistemas específicos informatizados $(12,12 \%)$, conforme a Figura 7.

Isto mostra que pelo menos $27,27 \%$ dos entrevistados estão preocupados em gerenciar seus projetos de forma mais eficiente, uma vez que, na Organização, o preenchimento da planilha de apropriação de atividades é obrigatório.

Sabe-se que as informações registradas no atual sistema de acompanhamento de projetos da Organização têm tratamento inadequado e uma divulgação limitada. Na tentativa de identificar os problemas inerentes à administração de projetos da Organização, foram preparadas questões específicas sobre os fatores críticos de sucessos/fracassos obtidos da literatura técnica.

$\mathrm{O}$ primeiro fator a ser estudado refere-se à definição de objetivos. Neste sentido verificou-se que os objetivos dos projetos da amostra foram bem definidos e compreendidos (84\%) pela equipe, o que pode comprovar o sucesso destes projetos, uma vez que fazem parte do universo dos 50 maiores projetos em receitas da Organização, cujo indicador receita sobre despesas (r/d) foi sempre maior que um.

Foi constatado que a maioria dos entrevistados participa de projetos em que se discutem os objetivos de forma ampla com o envolvimento de toda a equipe (52\%). No entanto, conforme mostra a Figura 8, percebe-se que os objetivos muitas vezes são de domínio apenas de algum membro envolvido no âmbito do projeto: gerente (36\%), diretoria (4\%) ou líderes de equipe (8\%).

Figura 8: Discussão e difusão dos objetivos de projetos

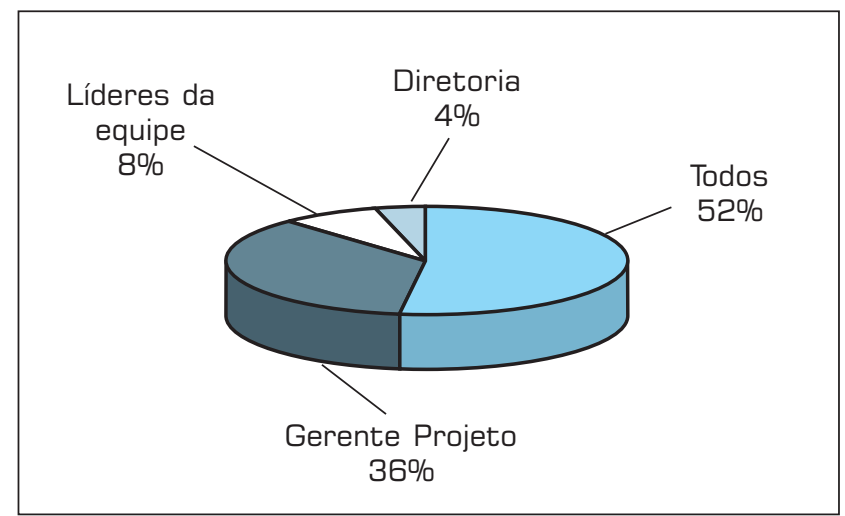

Figura 7: Formas de sistematização de informação de projetos

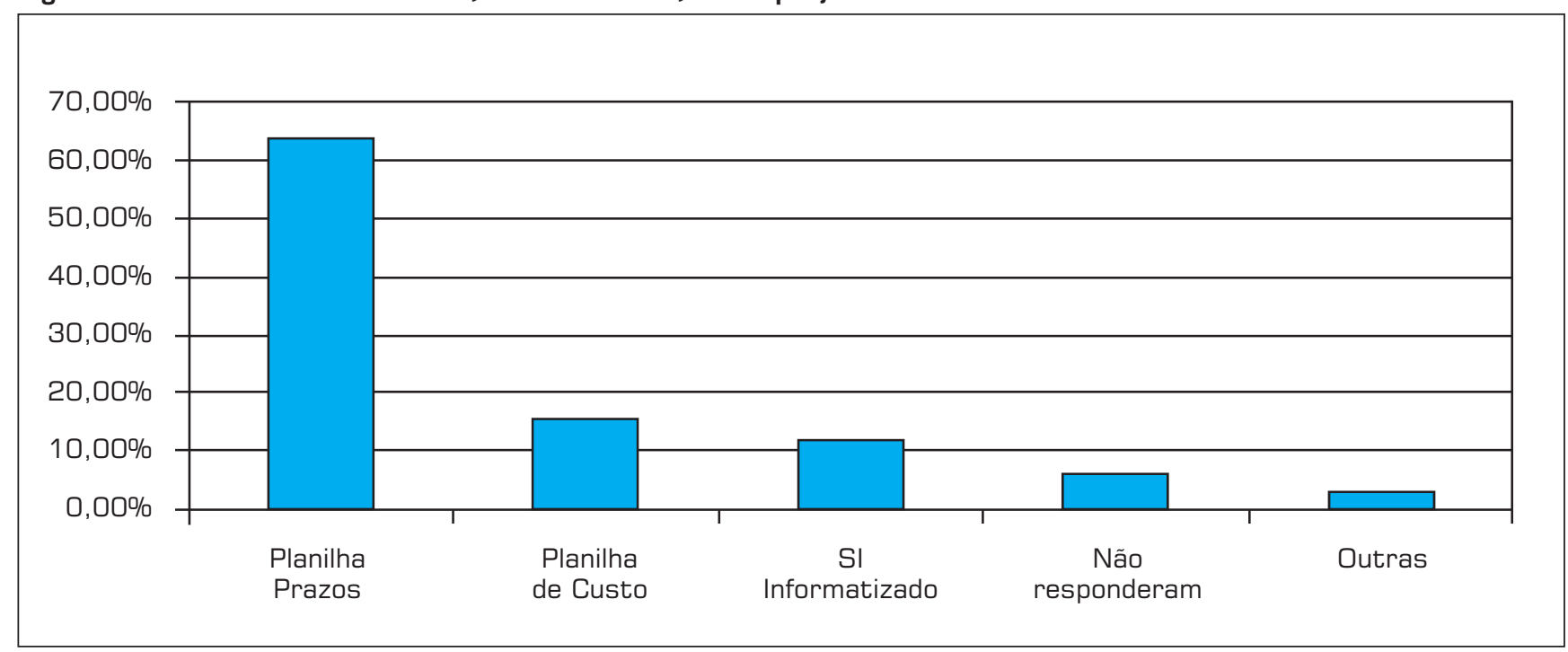


Um outro ponto levantado na pesquisa foi a interação com o cliente. Percebeu-se que há pelo menos três formas pelas quais o cliente interage com o projeto. A interação mais forte verificou-se em $44 \%$ dos casos, nos quais o cliente chega a participar efetivamente da equipe de projetos. Também merece destaque o envolvimento do cliente nas fases marcantes do projeto (32\%), quando faz avaliações e validações nos produtos intermediários. Por fim, verificou-se que há casos $(20 \%$ deles) em que o cliente tem um relacionamento mais distante com o projeto, ou seja, com interação menos intensa, de maneira que participa apenas das decisões de aceite ou recusa das fases do projeto. A Figura 9 mostra estas principais formas de interação do cliente com o projeto.

Figura 9: Interação com o cliente.

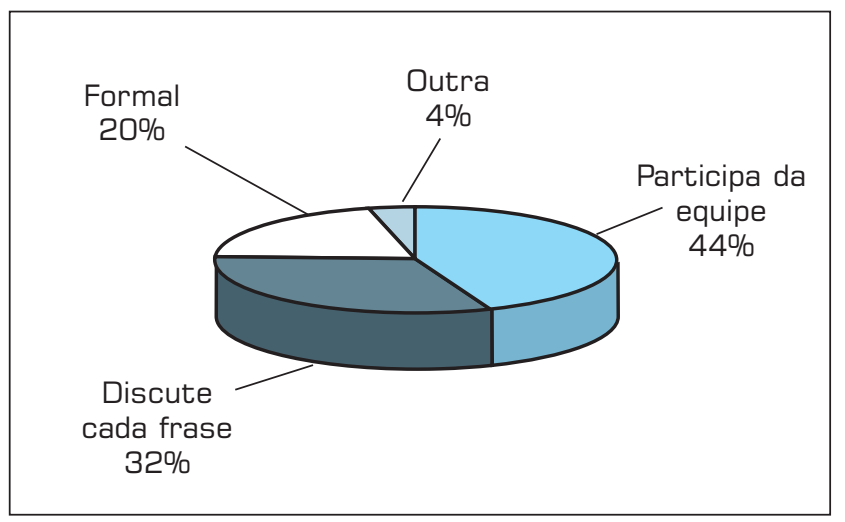

A ordem de importância das habilidades de um gerente de projeto percebida pelos entrevistados está expressa na Tabela 2. As três habilidades mais importantes perce- bidas foram: relacionamento humano, liderança e técni$c a$, sendo que relacionamento humano e liderança estão entre os três primeiros tanto para os técnicos quanto para os gerentes. As habilidades menos importantes foram orçamento, comunicação e relacionamento com clientes e fornecedores. No entanto, verificou-se uma discrepância quanto à classificação da habilidade "relacionamento com clientes e fornecedores", que na ordem geral ficou em sexto lugar mas que para os gerentes mereceria ocupar a terceira posição.

Nota-se também que houve um empate na sexta posição dada pelos gerentes, referente às habilidades de comunicação e gerência de prazo.

A pesquisa não revelou a causa que resultou em tal classificação. No entanto, mostrou os principais pontos de divergência (e algumas convergências) entre a opinião dos técnicos e dos gerentes de projetos.

A Figura 10 mostra que orçamento, comunicação e relacionamento humano são as habilidades em que a opinião dos técnicos e dos gerentes de projetos está mais próxima. E que, de forma geral, há mais divergências entre as opiniões do que convergências, merecendo destaque as habilidades "técnica" e "administração do tempo" como sendo as em que as opiniões estão mais distantes.

Uma análise mais profunda nos resultados referentes às opiniões sobre habilidades poderá indicar, mesmo que de forma empírica, alguns caminhos no sentido de ações estratégicas da Organização, tanto no campo do treinamento quanto no da implementação de um sistema de gerência de projetos institucional. Por exemplo, um treinamento deverá considerar as divergências e as carências encontradas na pesquisa, para que seu conteúdo aborde e valorize tais aspectos. Do lado da implementação, um plano válido deverá considerar as idiossincrasias existentes em cada

Tabela 2: Ranking das habilidades percebidas.

\begin{tabular}{|l|c|c|c|c|}
\hline \multicolumn{1}{|c|}{$\begin{array}{c}\text { Habilidades do } \\
\text { Gerente de Projetos }\end{array}$} & $\begin{array}{c}\text { Ordem } \\
\text { Técnicos }\end{array}$ & $\begin{array}{c}\text { Ordem } \\
\text { Gerentes }\end{array}$ & Geral & Participação \\
\hline $\begin{array}{l}\text { Capacidade em gerenciar as relações humanas, } \\
\text { resolvendo conflitos e estimulando as pessoas. }\end{array}$ & 3 & 1 & 1 & $87,20 \%$ \\
\hline Capacidade de estabelecer metas e de fazer cumpri-las. & 2 & 2 & 2 & $82,40 \%$ \\
\hline Capacidade em definir o objetivo e escopo do projeto. & 1 & 5 & 3 & $78,40 \%$ \\
\hline Capacidade de gerenciar o prazo das atividades do projeto. & 4 & 6 & 4 & $77,60 \%$ \\
\hline $\begin{array}{l}\text { Capacidade em negociar com as várias entidades que } \\
\text { participam do projeto. }\end{array}$ & 5 & 4 & 5 & $76,80 \%$ \\
\hline Capacidade em contratar fornecedores e de se relacionar com clientes & 6 & 3 & 6 & $75,20 \%$ \\
\hline Capacidade em estabelecer um sistema de informação no projeto & 7 & 6 & 7 & $71,20 \%$ \\
\hline $\begin{array}{l}\text { Capacidade em elaborar egerenciar planos financeiros e de } \\
\text { desembolso do projeto }\end{array}$ & 8 & 7 & 8 & $64,80 \%$ \\
\hline
\end{tabular}


Figura 10: Percepção das habilidades: gerentes $X$ técnicos.

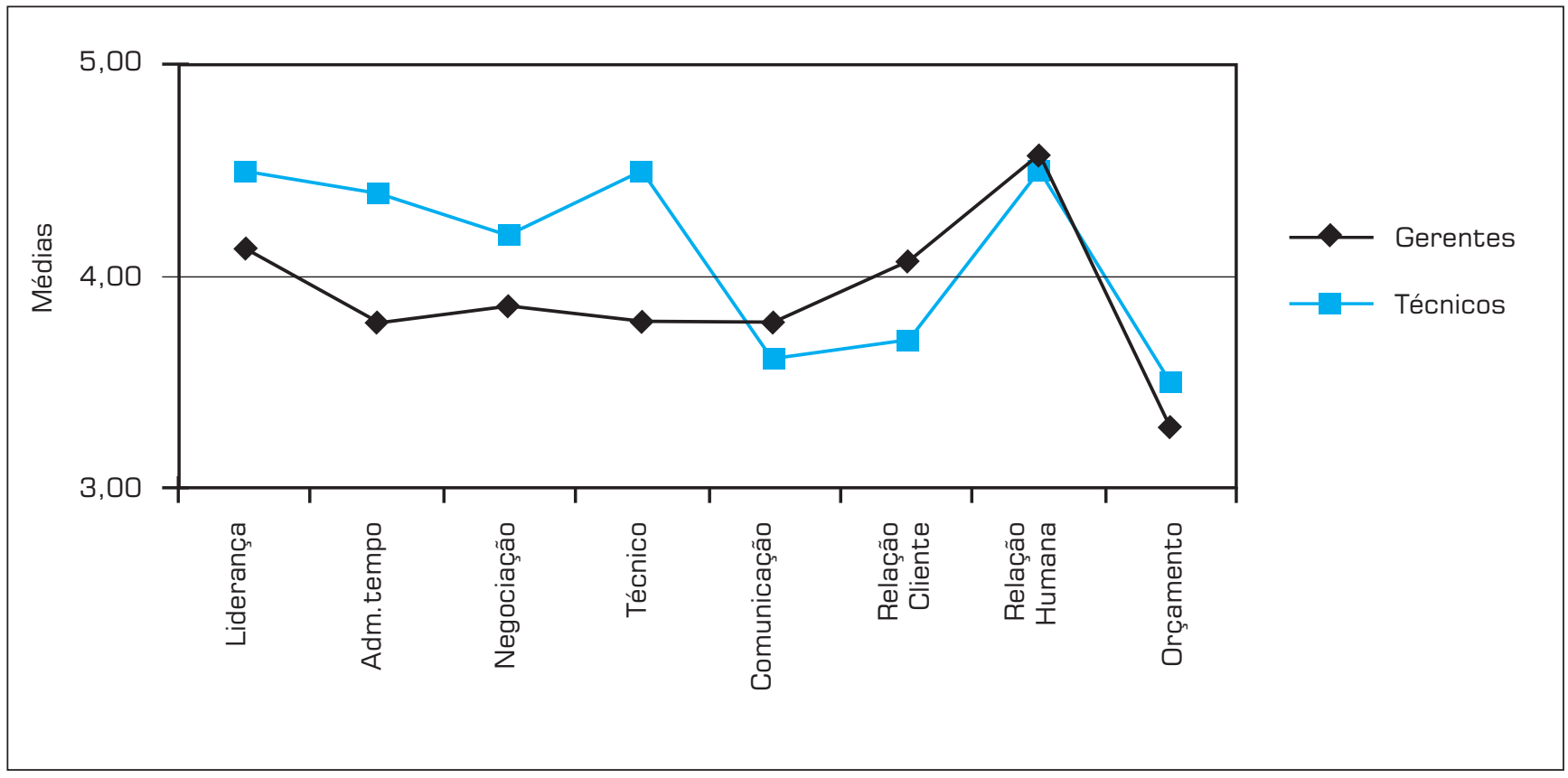

grupo (técnicos ou gerentes) para garantir o sucesso no sistema final.

Os dados sobre planejamento do projeto revelaram que os técnicos $(76 \%)$ participam intensamente na elaboração do plano do projeto. No entanto a pesquisa revelou que, $56 \%$ dos entrevistados fazem planejamento sob regras da disciplina gerência de projetos, incluindo o cliente na elaboração do cronograma, além de registrar tal ato na proposta final. Mas existe um contingente deles (44\% dos entrevistados) que pouco se preocupam com a qualidade do planejamento e que, pelas respostas apresentadas, não seguem regras rígidas e elaboram as agendas apenas para constar formalmente nas propostas finais.

Um outro dado extraído da pesquisa refere-se à alocação de horas que os técnicos dedicam aos projetos. Esta atividade, em grande parte (68\%) é feita pelos gerentes de projetos, que montam as equipes para em seguida negociarem as horas previstas.

A negociação destas horas algumas vezes ocorre não com os técnicos mas com os gerentes funcionais (16\%). Foi mencionado também, por $16 \%$ dos entrevistados, que a negociação das horas dos técnicos em projetos se dá através da discussão caso a caso (Figura 11).

O consumo de horas em projetos também foi medido e, verificou-se que elas têm sido gastas de acordo com o planejado, na maioria dos casos (56\%). No entanto há uma parcela significativa $(40 \%)$ das horas previstas de técnicos em projetos que ultrapassa o que foi inicialmente planejado (sendo que $4 \%$ não responderam).
Figura 11: Forma de apropriação de horas em projetos.

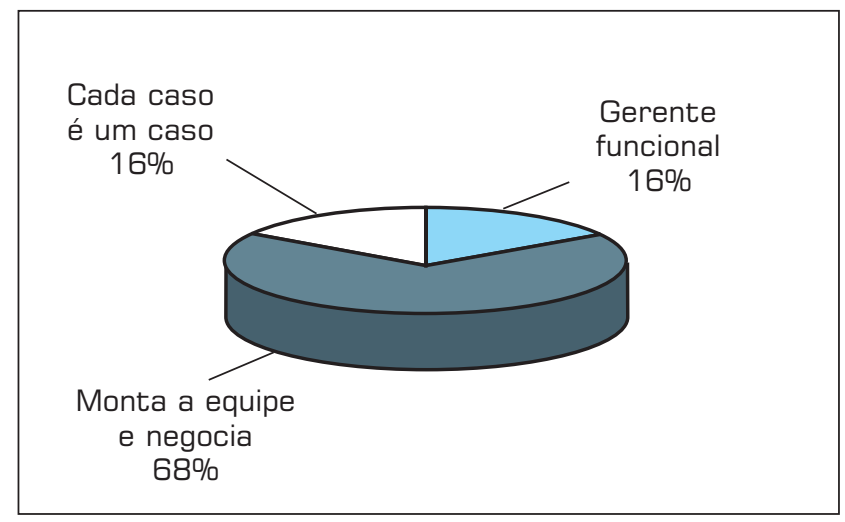

Figura 12: controle de custos de projetos.

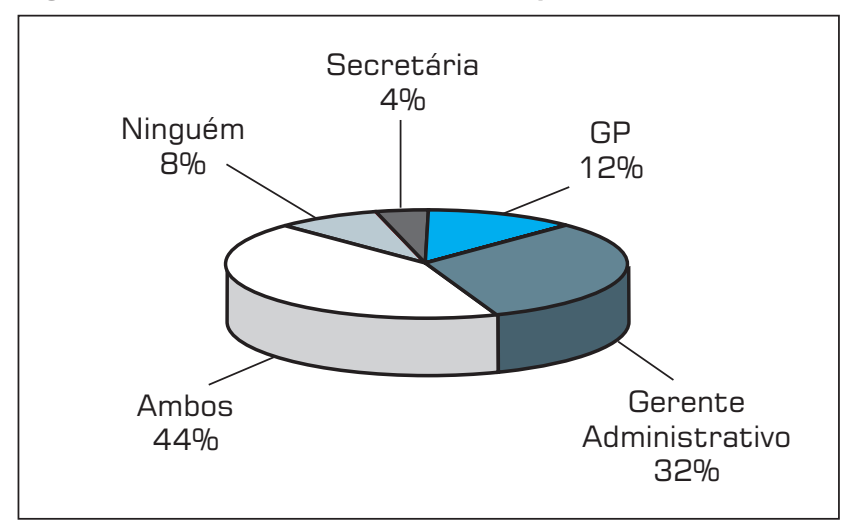


As informações referentes ao controle de custos dos projetos revelam que apenas em $12 \%$ dos casos esta atividade é desenvolvida pelo gerente de projetos. O gerente administrativo é o elemento que mais absorve as tarefas referentes ao controle de custos (32\%). Na maioria dos casos (44\%), o controle é exercido por ambos - o gerente de projetos e o gerente funcional. É surpreendente notar também que em $8 \%$ dos casos foi mencionada a inexistência de controle (ninguém), conforme a Figura 12.

Com relação aos custos do projeto, a maioria dos entrevistados (72\%) respondeu que os projetos terminam com um custo real equivalente ao planejado. No entanto existe uma parcela de $20 \%$ que mencionaram que os custos reais superam os planejados (8\% não responderam).

Por fim, a questão da comunicação foi levantada considerando-se dois aspectos: um, mostrando que a informação sobre as etapas do projeto é estruturada através de reuniões periódicas (45\%), pela comunicação via oral (38\%), utilizando-se de mensagens de correio eletrônico (13\%) e por meio de circulares (4\%). A Figura 13 mostra estas porcentagens.

\section{Figura 13: Meios de comunicação em projetos.}

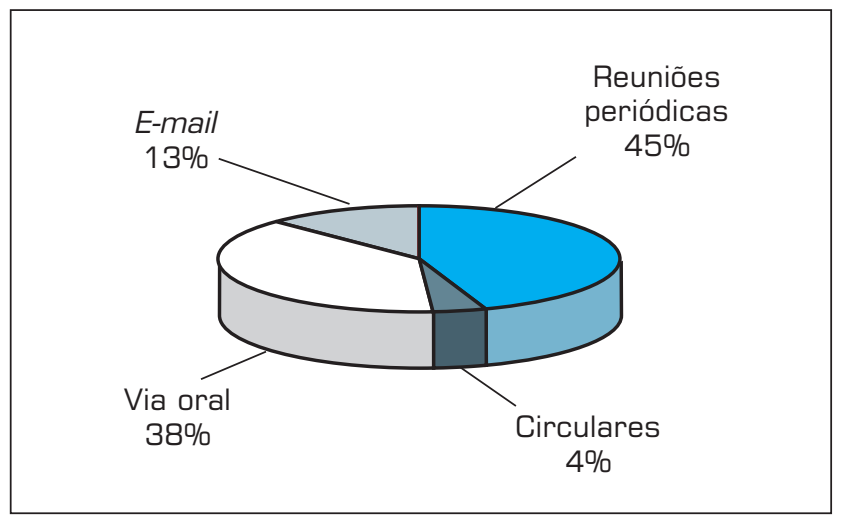

A outra mostrou que, $80 \%$ dos entrevistados têm conhecimento das etapas de seus projetos e apenas $12 \%$ declararam que não têm informações sobre seus projetos (os restantes não responderam).

\section{CONSTATACCÕES RELEVANTES AO AMBIENTE DE GERÊNCIA DE PROJETOS DA ORGANIZACCÃO.}

Alguns fatores relevantes foram identificados para efeito de análise das informações levantadas, efetuada sob o âmbito de duas dimensões: uma de âmbito estratégico, que considera a Organização e a implementação da metodologia de Gerência de Projetos como uma nova opção de gerenciamento; outra, tática, que relaciona os elementos a serem considerados na implementação de tal metodologia. Assim, os fatores de ordem estratégica, foram assim discriminados: a) vontade política dos envolvidos, b) adequação da estrutura organizacional, c) aproveitamento das abordagens existentes, d) implementações frustradas e, e) objetivos e planejamento de projetos. Os fatores táticos referem-se à gerência de: a) recursos, b) custo, c) prazo, d) habilidades pessoais, e) cliente/equipe, f) comunicação, g) técnica e h) sistematização das atividades. Os fatores identificados certamente têm um nível bastante alto de relacionamento e foram assim agrupados para efeito de análise.

A relação destes fatores, acompanhada de uma avaliação subjetiva feita pela equipe de projetos da intensidade de seus impactos, está expressa na Tabela 3. A representação da avaliação é feita através da quantidade de pontos (máximo de 5 e mínimo de 1), sendo que uma maior quantidade significa maior impacto do fator na empresa.

Uma das constatações mais importantes observadas no trabalho foi o papel que a alta administração da Organização deve desempenhar num empreendimento deste porte. Os fracassos em implementações de projetos da natureza de uma Organização de Pesquisas acontecem quando a alta administração está ausente, principalmente no que concerne às questões de mudanças, que são muitas e geram conflitos de várias dimensões. Administrá-las requer uma participação ativa e constante.

A estrutura da Organização é um outro fator que merece atenção, uma vez que apresenta acentuada característica departamental e hierarquizada, constituída de cinco níveis. Estas duas características são classicamente inibidoras da gestão por projetos, pois reduzem de forma significativa a autonomia dos gerentes e das equipes de projeto. Desta forma pode-se caracterizar a estrutura como matricial fraca, uma vez que está mais parecida com a estrutura funcional e os gerentes funcionais possuem um maior poder em comparação aos gerentes de projeto.

O planejamento da implementação de um sistema de gerência de projetos e seus objetivos foi identificado como um fator amplo composto de três fatores relacionados: a) aproveitamento das experiências existentes, b) implementações frustradas e c) do fator tático: sistematização das atividades. Ou seja, foi detectado pela pesquisa que há um grande contingente de pesquisadores na Organização que preenchem a planilha de apropriação das horas trabalhadas. Sendo assim, o referido planejamento deverá considerar este esforço já incorporado pelos pesquisadores. Ademais, foi verificado que pelo menos uma das experiências desenvolvidas internamente considera este sistema de apropriação de horas.

O planejamento em si é justificado pela existência, verificada, de experiências frustradas de implementação de programas de gerência de projetos. A inexistência desta etapa, segundo vários autores (KERZNER, 1992), (KING, 
1983), (STHUB, et al., 1994), implica em fracasso certo.

Sobre os fatores de ordem tática, constatou-se que a adequação de recursos de projetos torna-se um benefício tangível e explicitamente obtido através da implementação da metodologia de gerência de projetos. Após planejamento e implementação da metodologia de gerência de projetos, através do uso de programas de computador já consolidados no mercado, é possível elaborar facilmente o nivelamento de recursos em projetos.

Em relação aos custos dos projetos pesquisados, constatou-se que $20 \%$ deles ultrapassam seu planejamento inicial. Não foram verificadas as causas destas ocorrências, nem se elas têm a concordância do cliente. A porcentagem obtida, no entanto, não reflete a importância deste item, que, por ser tão escasso e fundamental no âmbito da Organização, tornase extremamente necessário que seja bem administrado.

O prazo referente ao planejamento de projetos é um fator também bastante crítico, uma vez que se percebeu a existência de um índice significativo de projetos que não cumprem a previsão inicial (40\%).

Os fatores finais, "comunicação" e "técnica", não apresentaram nível de preocupação inicial. Atualmente, com a proliferação do uso da Internet, a comunicação entre as equipes e técnicos envolvidos nos projetos torna-se cada vez mais acessível, facilitando a troca de informações entre projetos. No entanto, não foi verificada a qualidade da informação que circula pela rede. Sabe-se que, sem a existência de um programa adequado de gerenciamento de projetos, a informação transmitida tem função gerencial limitada.

De acordo com os resultados, a Organização encontra-se posicionada na fase de reconhecimento pela alta administração, conforme sugerido pelo modelo de maturidade em gestão de projetos de Kerzner (2001), pois o reconhecimento da gerência de linha ainda não foi atingido. Aliada a este fato, destaca-se a tímida preocupação com a formação de competências em gestão de projetos e com o auto-desenvolvimento, tendo em vista o desenvolvimento de habilidades nas nove áreas de conhecimento desta disciplina, conforme sugerido por PMBoK (2000), itens necessários para se atingir a maturidade.

A identificação das lacunas de uma Organização no desenvolvimento de uma metodologia de gerenciamento de projetos, com base nos modelos teóricos estudados, mostrou-se uma ferramenta eficiente para o diagnóstico do estágio da gestão de projetos para corporação, orientando as ações de melhoria e a formulação de um programa de desenvolvimento, visando atingir a maturidade e posteriormente a excelência em projetos.

Paralelamente, este estudo discutiu os fatores críticos referentes ao desenvolvimento de projetos no âmbito de uma organização de pesquisa, apresentando um quadro detalhado das práticas de gerenciamento de projetos neste tipo de organização, que serviu como referência analítica para aplicação dos modelos teóricos.

Tabela 3: Agrupamento de fatores estratégicos e táticos.

\begin{tabular}{|l|c|}
\hline \multicolumn{1}{|c|}{ Fatores } & Impacto \\
\hline Dimensão Estratégica & \\
\hline Vontade Política dos Envolvidos & \\
\hline Adequação Estrutura Organizacional & \\
\hline Aproveitamento Abordagens Existentes & \\
\hline Implementaçães Frustradas & \\
\hline Objetivos e Planejamento & \\
\hline Dimensão Tática & \\
\hline Adequação de Recursos & \\
\hline Custos & \\
\hline Prazo & \\
\hline Habilidades Gerenciais & \\
\hline Participação do Cliente/Equipe & \\
\hline Comunicação & \\
\hline Técnicas & \\
\hline Sistematização de Atividades & \\
\hline
\end{tabular}




\section{CONCLUSÃO}

Este trabalho apresentou um quadro caracterizando os fatores críticos de sucesso de projetos relevantes em uma organização de pesquisa tecnológica. A constituição deste quadro foi decorrente de um diagnóstico, no qual foram entrevistados pesquisadores e examinados projetos considerados fundamentais para a organização.

Os fatores obtidos foram reunidos em dois grupos: os de origem estratégica e os táticos. O agrupamento e a avaliação destes fatores são alguns dos elementos que este trabalho traz à tona no intuito da caracterização de gerenciamento de projetos em organizações de pesquisas tecnológicas. Neste sentido, é possível constituir um quadro referencial que aponte para ações consistentes em gerenciamento de projetos, vindo assim contribuir para o fórum de discussão sobre este importante tema.
A importância de estudos desta natureza reside na proposição de uma forma de gerenciar a carteira de projetos de inovação, disponibilizando o diagnóstico dos fatores relevantes, com a respectiva avaliação de seus impactos, aos responsáveis por projetos nas organizações de pesquisa tecnológica. Esta ferramenta, mesmo que analítica, consiste em relevante apoio ao processo de tomada de decisão e construção de um plano de ação.

Por outro lado, alguns fatores foram limitantes no âmbito deste estudo, o que, contudo, não constituem restrições aos seus resultados. Acredita-se que uma expansão da amplitude da amostra poderia trazer resultados mais significativos para a análise neste caso específico.

Por fim, observa-se que a pesquisa não se preocupou em alinhar os fatores identificados com as diretrizes de ações em gerenciamento de projetos, o que pode ser um objeto para uma agenda futura de estudo.

\section{- Referências bibliográficas}

CARVALHO, M.M. QFD: uma ferramenta de tomada de decisão em projeto. Tese (Doutorado) Departamento de Engenharia Produção e Sistema, Universidade Federal de Santa Catarina Florianópolis, 1997 . http:// www.eps.ufsc.br/teses $97 / \mathrm{marly} /$ index.html

CARVALHO, M.M.; MACHADO, S.A PIZYSIEZNIG FILHO, J.; RABECHINI Jr., R. Fatores Críticos de Sucesso em empresas de base tecnológica. Produto \& Produção, vol.4, número especial, p. 47-59, Porto Alegre, 2000 .

CARVALHO, M.M.; LAURINDO, F.J.B.; PESSÔA, M.S.P. Applying Efficiency Models in Information Technology Area of Brazilian Companies. In: IRMA 2002 - Information Resources Management Association International Conference: "Issues and Trends of Information Technology Management in Contemporary Organizations", Proceedings, p. 109-110, Seattle, USA, May 19-22, 2002.

DE MASI, D. O ócio criativo. Rio de Janeiro: Sextante, 328p, 2000.

DUHAN, S; LEVY, M; POWELL, P. Information systems strategies in knowledge-based SMEs: the role of core competencies. European Journal of Information Systems 10, p. 25-40, 2001.
EARDLEY, A.; LEWIS, T.; AVISON, D.; POWELL, P. The Linkage between IT and Business Competitive Systems: a Reappraisal of Some 'Classic' Cases Using a Competitive Analysis Framework. International Journal of Technology Management, v.11, n.3/4 p.395-411, 1996.

FRAME, J.D. Project Management Competence: Building Key Skills for Individuals, Teams, and Organizations. Jossey-Bass Publishiers, San Francisco, 1999.

HANDY, C. A era do paradoxo. Rio de Janeiro : Makron Books, p. 229, 1995.

INTERNATIONAL STANDARD ORGANIZATION. ISO 10006: Quality management - Guidelines to quality in project management. s.l.p., ISO, 1997.

KANTER, R. M. Inovação. São Paulo: Negocio Editora, 194p., 1998.

KERZNER, H. Applied Project Management Best Practices on Implementation. John Wiley \& Sons, USA, 2000.

KERZNER, H. Project Management: a systems aprouch to planning, scheduling and controlling. Van Nostrand Reinhold, New York, 1992.
KING, W.R. The Role of Projects in the Implementation of Business Strategy. In: CLELAND, D. I.; KING, W, R. Project Management Handbook. Van Nostrand Reinhold, New York, 1983.

LANDGRAF, J.G. et al. Uma visão do IPT acerca da Qualidade Total em PED. São Paulo, Relatório Interno IPT, 1994.

MAXIMIANO, A.C.A. O Gerente de Projetos: um "ator" com vários personagens. Revista de Administração, São Paulo 23 (2), 93-98 abr-jun, 1988.

MEREDITH, J. R. ; MANTEL Jr., S. J. Project Management A managerial Approach. John Wiley \& Sons, Inc: New York, 1995.

PINTO, J.K. \& D.P.SLEVIN. Critical Factors in Successful Project Implementation in: CLELAND, D. I.; KING, W, R. Project Management Handbook. Van Nostrand Reinhold, New York, 1983.

PORTER, M. Clusters and the new economics os competitions. Harvard Business Review, nov-dec, p.77-90, 1998.

PROJECT MANAGEMENT INSTITUTE PMI. Guide of Project Management Body of Knowledge - PMBOK, 2000.

RABECHINI JR., R. ; YU, A. S. O ; CORREA, E. S. O Monitoramento Tecnológico $E$ as Decisões nas Empresas. In: XIX Simpósio da Gestão da Inovação Tecnológica, São Paulo, outubro, 1996.
SBRAGIA, R.A. Interface entre Gerentes de Projeto e Gerentes Funcionais em Estruturas Matriciais. Revista de Administração, São Paulo 20 (2), 48-55 abr-jun, 1985.

SHTUB, A. ; BARD, J. F. ; GLOBERSON, S. Project Management Engineering, Technology and Implementation, Prentice Hall, New Jersey, 1994.

TERRA, J.C.C. Gestão do Conhecimento: Aspectos Conceituais e Estudo Exploratório Sobre as Práticas de Empresas Brasileiras. Tese de Doutorado Departamento de Engenharia de Produção da Escola Politécnica da Universidade de São Paulo, 1999.

TIDD, J. ; BESSANT, J. ; PAVITT, K. Managing Innovation Integrating Technological, Market and Organizatioinal Change, John Wiley \& Sons, New York, 1997.

TUMAN, G.J. Development and Implementation of Effective Project Management Information and Control Systems, In: CLELAND, D. I.; KING, W, R. Project Management Handbook. Van Nostrand Reinhold, New York, 1983.

YIN, R.K. Case Study Research: Design and Methods. Newbury Park, Rev. ed. Sage Publications, 1991. 